INDEPENDENCE BEFORE CONSERVATISM:

Transparency, Politics, and Central Bank Design

by

Andrew Hughes Hallett and Diana N. Weymark

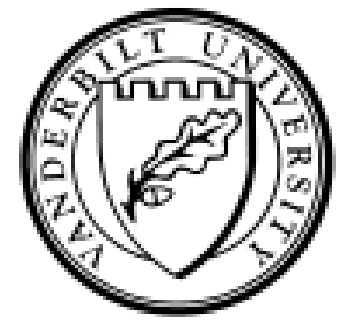

Working Paper No. 02-W02

March 2002

DEPARTMENT OF ECONOMICS

VANDERBILT UNIVERSITY

NASHVILLE, TN 37235

www.vanderbilt.edu/econ 


\title{
Independence Before Conservatism: Transparency, Politics, and Central Bank Design
}

\author{
by \\ Andrew Hughes Hallett
Department of Economics,
Vanderbilt University,
Nashville, TN
a.hugheshallett@vanderbilt.edu
Diana N. Weymark
Department of Economics,
Vanderbilt University,
Nashville, TN 37235, USA
diana.weymark@vanderbilt.edu
}

March 2002 


\section{Abstract \\ Independence Before Conservatism: Transparency, Politics, and Central Bank Design}

The problem of monetary policy delegation is formulated as a two-stage game between the government and the central bank. In the first stage the government chooses the institutional design of the central bank. Monetary and fiscal policy are implemented in the second stage. When fiscal policy is taken into account, there is a continuum of combinations of central bank independence and conservatism that produce optimal outcomes. This indeterminacy is resolved by appealing to practical considerations. In particular, it is argued that full central bank independence facilitates the greatest degree of policy transparency and political coherence.

Journal of Economic Literature Classification No.: E52.

Keywords: central bank independence, central bank conservatism, monetary policy delegation, transparency, policy coherence 


\section{Introduction}

It is now widely accepted that the design of central banking institutions plays a fundamental role in determining economic performance. In both academic and policymaking circles, questions of optimal central bank design have centered around the twin pillars of central bank independence and conservatism. The consensus view that has emerged from the large literature on this topic is that inflation control requires the establishment of a central bank that is independent of the fiscal authority and that is also more conservative in its response to output disturbances than the fiscal authority. While considerable attention has been devoted to determining the optimal degree of conservatism when it is assumed that the central bank is fully independent, it is only recently that the problem of jointly determinint the optimal degrees of central bank conservatism and independence has been addressed. Weymark (2001) has shown that there will generally be a continuum of combinations of central bank conservatism and independence that minimize the government's loss function. In this article, we argue that by taking into account further aspects of central bank design, it is possible to determine which of these combinations should be chosen.

Rogoff (1985) was the first to suggest that a conservative central banker is the key to solving the problem of inflationary bias in monetary policy. However, Rogoff also noted that too much conservatism could be harmful because the central bank would then underreact to output disturbances. Thus, in Rogoff's analysis, and in the numerous contributions that build on it, there is a conflict between the credibility of monetary policy implemented by an independent and conservative central bank and the flexibility of the central bank's response to output shocks. ${ }^{1}$ Using a model that is very similar to Rogoff's, Lohmann (1992) has shown that when output disturbances are large, it is in society's best interest to give up some credibility in exchange for greater flexibility. In Lohmann's framework, the increase in flexibility is achieved by providing the government with the legal right to override the central bank in times

\footnotetext{
${ }^{1}$ See, for example, Flood and Isard (1989), Cukierman (1992), and Eijffinger and Schaling (1996).
} 
of exigency.

Two features of the models used by Rogoff and Lohmann are responsible for the conflict between credibility and flexibility that arises in their analyses. First, both models treat the degree of central bank independence as exogenous. Consequently, the combinations of independence and conservatism that are considered could easily be sub-optimal. Second, neither model formally recognizes the potential interaction between monetary and fiscal policy in determining economic outcomes. ${ }^{2}$ Because monetary policy is the only policy instrument available, credibility and flexibility objectives cannot be achieved simultaneously. Weymark (2001) models central bank independence and conservatism as outcomes of a strategic game between the government and the central bank. In her model, the conflict between credibility and flexibility is resolved because a second policy instrument, fiscal policy, can be directed towards maintaining flexibility. ${ }^{3}$

As noted above, Weymark did not identify a unique optimal combination of central bank conservatism and independence. We show that practical aspects of policy design, such as the desirability of transparency, can be used to resolve this indeterminacy. Our theoretical results demonstrate that a lesser degree of central bank independence can always be compensated by appointing more conservative central bankers. However, our results also show that the optimal degree of central bank independence is decreasing in the divergence between the importance that the central bank and the government assign to output growth. Our calculations for a sample of eight OECD countries suggest that the optimal trade-off between independence and conservatism is quite steep, so that relatively small departures from full independence require very large increases in central bank conservatism.

\footnotetext{
${ }^{2}$ Alesina and Tabellini (1987) and Debelle and Fischer (1994) employ models in which there is strategic interaction between the fiscal and monetary authorities, but they do not endogenize the degree of central bank independence.

${ }^{3}$ A study by Eijffinger and Hoebrichts (1998), in which independence and conservatism are identified as potential substitutes when optimized, provides empirical support for Weymark's theoretical results. Eijffinger and Hoebrichts, however, still operate with a single (monetary) instrument.
} 
In a world where private agents have limited information about the economy and policy objectives, policy effectiveness is enhanced by transparency and accountability. An institutional design that decreases the perceived cohesiveness between monetary and fiscal policy is likely to undermine the benefits of transparency and thus reduce policy effectiveness. Our discovery that relatively small departures from full independence must be offset by a large divergence in the policy stances of the two policy authorities leads us to conclude that, in practice, more central bank independence is better than less and that the best economic outcomes will be achieved under full central bank independence.

The rest of this article is organized as follows. The theoretical framework is presented in Section 2. In Sections 3 and 4 we consider alternative configurations of optimal central bank design. Empirical evidence from eight OECD countries is presented and analyzed in Section 5. The relationship between independence, conservatism, and transparency is discussed in Section 6. Section 7 concludes.

\section{Economic Structure}

The model used in Weymark (2001) provides a useful framework for the present analysis. For purposes of exposition, we suppress potential spillover effects between countries and focus on the following three equations to represent the economic structure of any country:

$$
\begin{gathered}
\pi_{i t}=\pi_{i t}^{e}+\alpha_{i} y_{i t}+u_{i t} \\
y_{i t}=\beta_{i}\left(m_{i t}-\pi_{i t}\right)+\gamma_{i} g_{i t}+\epsilon_{i t} \\
g_{i t}=m_{i t}+s_{i}\left(b_{i} y_{i t}-\tau_{i t}\right)
\end{gathered}
$$

where $\pi_{i t}$ is the inflation rate in country $i$ in period $t, y_{i t}$ is output growth in country $i$ in period $t$, and $\pi_{i t}^{e}$ represents the rate of inflation that rational agents expect will prevail in country $i$ in period $t$, conditional on the information available at the time expectations are formed. The variables $m_{i t}, g_{i t}$, and $\tau_{i t}$ represent, respectively, the growth in the money supply, government expenditures, and tax revenues in the $i$ th 
country in period $t$. The variables $u_{i t}$ and $\epsilon_{i t}$ are random disturbances which are assumed to be independently distributed with zero mean and constant variance. The coefficients $\alpha_{i}, \beta_{i}, \gamma_{i}, s_{i}$, and $b_{i}$ are all positive.

According to (1), inflation is increasing in the rate of inflation predicted by private agents and in output growth. Equation (2) indicates that both monetary and fiscal policies have an impact on the output gap. The microfoundations of the aggregate supply equation (1), originally derived by Lucas $(1972,1973)$, are well-known. McCallum (1989) shows that aggregate demand equations like (2) can be derived from a standard, multiperiod utility-maximization problem.

Equation (3) describes the government's budget constraint. In the interests of simplicity, we allow discretionary tax revenues to be used for redistributive purposes only. Thus, in each period, the government must finance its remaining expenditures by selling government bonds to the central bank or to private agents. We assume that there are two types of agents, rich and poor, and that only the rich use their savings to buy government bonds. In (3), $b$ is the proportion of pre-tax income (output) that goes to the rich and $s$ is the proportion of after-tax income that the rich allocate to saving. The tax, $\tau_{i t}$, is used by the government to redistribute income from the rich to the poor.

Using (1), (2), and (4) to solve for $\pi_{i t}^{e}, \pi_{i t}$ and $y_{i t}$ yields the following reduced forms:

$$
\begin{aligned}
\pi_{i t}\left(g_{i t}, m_{i t}\right) & =\left(1+\alpha_{i} \beta_{i}\right)^{-1}\left[\alpha_{i} \beta_{i} m_{i t}+\alpha_{i} \gamma_{i} g_{i t}+m_{i t}^{e}+\frac{\gamma_{i}}{\beta_{i}} g_{i t}^{e}+\alpha_{i} \epsilon_{i t}+u_{i t}\right] \\
y_{i t}\left(g_{i t}, m_{i t}\right) & =\left(1+\alpha_{i} \beta_{i}\right)^{-1}\left[\beta_{i} m_{i t}+\gamma_{i} g_{i t}-\beta_{i} m_{i t}^{e}-\gamma_{i} g_{i t}^{e}+\epsilon_{i t}-\beta_{i} u_{i t}\right] .
\end{aligned}
$$

Equations (5) and (3) then imply

$$
\begin{array}{r}
\tau_{i t}\left(g_{i t}, m_{i t}\right)=\left[s_{i}\left(1+\alpha_{i} \beta_{i}\right)\right]^{-1}[ \\
{\left[1+\alpha_{i} \beta_{i}+s_{i} b_{i} \beta_{i}\right) m_{i t}-\left(1+\alpha_{i} \beta_{i}-s_{i} b_{i} \gamma_{i}\right) g_{i t}} \\
\left.-s_{i} b_{i} \beta_{i} m_{i t}^{e}-s_{i} b_{i} \gamma_{i} g_{i t}^{e}+s_{i} b_{i} \epsilon_{i t}-s_{i} b_{i} \beta_{i} u_{i t}\right]
\end{array}
$$

Because countries have long histories of sovereignty, there will generally be differences with respect to the preferences for growth and for income distribution or social 
equality. We assume that such differences will be reflected in the types of governments that are voted into office, and write the national objectives as:

$$
L_{i t}^{g}=\frac{1}{2}\left(\pi_{i t}-\hat{\pi}\right)^{2}-\lambda_{i 1}^{g} y_{i t}+\frac{\lambda_{i 2}^{g}}{2}\left[\left(b_{i}-\theta_{i}\right) y_{i t}-\tau_{i t}\right]^{2}
$$

where $\hat{\pi}$ is the government's inflation target, $\lambda_{i 1}^{g}$ is the relative weight assigned to output growth, and $\lambda_{i 2}^{g}$ is the weight assigned to income redistribution. The parameter $\theta_{i}$ represents the proportion of output that the government of country $i$ would, ideally, like to allocate to the rich. ${ }^{4}$

We assume that national central banks may have objectives that are distinct from those of their national governments:

$$
L_{i t}^{c b}=\frac{1}{2}\left(\pi_{i t}-\hat{\pi}\right)^{2}-\left(1-\delta_{i}\right) \lambda_{i}^{c b} y_{i t}-\delta_{i} \lambda_{i 1}^{g} y_{i t}+\frac{\delta_{i} \lambda_{i 2}^{g}}{2}\left[\left(b_{i}-\theta_{i}\right) y_{i t}-\tau_{i t}\right]^{2}
$$

where $0 \leq \delta_{i} \leq 1$, and $\lambda_{i}^{c b}$ is the weight that the central bank in country $i$ assigns to output growth. The parameter $\delta_{i}$ measures the degree to which the central bank is forced to take the government's objectives into account when formulating monetary policy. The closer $\delta_{i}$ is to 0 , the greater is the independence of the central bank. The central bank is then said to be 'conservative' when $\lambda_{i}^{c b}<\lambda_{i 1}^{g}$.

\section{Optimal Central Bank Design}

We assume that the interaction between the each country's elected national government and its central bank can be described as a two-stage non-cooperative game in which the structure of the model and the objective functions are common knowledge. In the first stage, the government chooses the institutional parameters $\delta_{i}$ and $\lambda_{i}^{c b}$. The second stage is a simultaneous-move game in which the government and the monetary authority set their policy instruments, given the $\delta_{i}$ and $\lambda_{i}^{c b}$ values determined at the

\footnotetext{
${ }^{4}$ Our model generalizes Alesina and Tabellini (9187) in that fiscal and monetary policy affect both aggregate supply and aggregate demand; and because we have both growth and redistribution (social expenditure) targets.
} 
previous stage. The central bank is assumed to have full instrument independence and therefore controls the money supply $m_{i t}$. Private agents understand the game and form rational expectations for future prices in the second stage. Thus:

\section{Stage 1}

The government solves the problem

$$
\begin{aligned}
\min _{\delta_{i}, \lambda_{i}^{c b}} \mathrm{E} L_{i}^{g}\left(g_{i t}, m_{i t}, \delta_{i}, \lambda_{i}^{c b}\right)=\mathrm{E}\{ & \frac{1}{2}\left[\pi_{i t}\left(g_{i t}, m_{i t}\right)-\hat{\pi}\right]^{2}-\lambda_{i 1}^{g}\left[y_{i t}\left(g_{i t}, m_{i t}\right)\right] \\
& \left.+\frac{\lambda_{i 2}^{g}}{2}\left[\left(b_{i}-\theta_{i}\right) y_{i t}\left(g_{i t}, m_{i t}\right)-\tau_{i t}\left(g_{i t}, m_{i t}\right)\right]^{2}\right\}
\end{aligned}
$$

\section{Stage 2}

(i) Private agents form rational expectations about future prices before the shocks $u_{i t}$ and $\epsilon_{i t}$ are realized.

(ii) The shocks $u_{i t}$ and $\epsilon_{i t}$ are realized and observed by the government and by the central bank.

(iii) The government chooses $g_{i t}$, taking $m_{i t}$ as given, to minimize $L_{i}^{g}\left(g_{i t}, m_{i t}, \bar{\delta}_{i}, \bar{\lambda}_{i}^{c b}\right)$, where $\bar{\delta}_{i}$ and $\bar{\lambda}_{i}^{c b}$ indicates values determined in stage 1.

(iv) The central bank chooses $m_{i t}$, taking $g_{i t}$ as given, to minimize

$$
\begin{aligned}
L_{i}^{c b}\left(g_{i t}, m_{i t}, \bar{\delta}_{i}, \bar{\lambda}_{i}^{c b}\right)=\frac{\left(1-\bar{\delta}_{i}\right)}{2}\left[\pi_{i t}\left(g_{i t}, m_{i t}\right)-\hat{\pi}\right]^{2}-\left(1-\bar{\delta}_{i}\right) \bar{\lambda}_{i}^{c b}\left[y_{i t}\left(g_{i t}, m_{i t}\right)\right] \\
+\bar{\delta}_{i} L_{i}^{g}\left(g_{i t}, m_{i t}, \bar{\delta}_{i}, \bar{\lambda}_{i}^{c b}\right)
\end{aligned}
$$

This game can be solved by first solving the second stage of the problem for the

optimal money supply and government expenditure policies with $\delta_{i}$ and $\lambda_{i}^{c b}$ fixed; and then the first stage by substituting the stage 2 results into (9) and minimizing with respect to $\delta_{i}$ and $\lambda_{i}^{c b}$. The result is (Weymark, 2001):

$$
\pi_{i t}\left(\delta_{i}, \lambda_{i}^{c b}\right)=\hat{\pi}+\frac{\left(1-\delta_{i}\right) \beta_{i} \phi_{i} \lambda_{i}^{c b}}{\alpha_{i}\left[\beta_{i} \phi_{i}+\delta_{i} \gamma_{i} \Lambda_{i}\right]}+\frac{\delta_{i}\left[\beta_{i} \phi_{i}+\gamma_{i} \Lambda_{i}\right] \lambda_{i 1}^{g}}{\alpha_{i}\left[\beta_{i} \phi_{i}+\delta_{i} \gamma_{i} \Lambda_{i}\right]}
$$




$$
\begin{gathered}
y_{i t}\left(\delta_{i}, \lambda_{i}^{c b}\right)=\frac{-u_{i t}}{\alpha_{i}} \\
\tau_{i t}\left(\delta_{i}, \lambda_{i}^{c b}\right)=\frac{\left(1-\delta_{i}\right) \beta_{i} \gamma_{i} s_{i}\left(\lambda^{c b_{i}}-\lambda_{i 1}^{g}\right)}{\left[\beta_{i} \phi_{i}+\delta_{i} \gamma_{i} \Lambda_{i}\right] \lambda_{i 2}^{g}}-\frac{\left(b_{i}-\theta_{i}\right) u_{i t}}{\alpha_{i}} .
\end{gathered}
$$

where $\phi_{i}=1+\alpha_{i} \beta_{i}-\gamma_{i} \theta_{i} s_{i}$ and $\Lambda_{i}=1+\alpha_{i} \beta_{i}+\beta_{i} \theta_{i} s_{i}$ are positive; and where

$$
\begin{gathered}
\lambda_{i 2}^{g}\left(1-\delta_{i}\right) \phi_{i}\left\{\left(1-\delta_{i}\right) \beta_{i} \phi_{i} \lambda_{i}^{c b}+\delta_{i}\left[\beta_{i} \phi_{i}+\gamma_{i} \Lambda_{i}\right] \lambda_{1}^{g}\right\} \\
+\alpha_{i}^{2}\left(1-\delta_{i}\right)^{2} \beta_{i} \gamma_{i}^{2} s_{i}^{2}\left(\lambda_{i}^{c b}-\lambda_{i 1}^{g}\right)=0 \\
\lambda_{i 2}^{g} \phi_{i}\left\{\left(1-\delta_{i}\right) \beta_{i} \phi_{i} \lambda_{i}^{c b}+\delta_{i}\left[\beta_{i} \phi_{i}+\gamma_{i} \Lambda_{i}\right] \lambda_{i 1}^{g}\right\}\left(\lambda_{i}^{c b}-\lambda_{i 1}^{g}\right) \\
+\alpha_{i}^{2}\left(1-\delta_{i}\right) \beta_{i} \gamma_{i}^{2} s_{i}^{2}\left(\lambda_{i}^{c b}-\lambda_{i 1}^{g}\right)^{2}=0 .
\end{gathered}
$$

are the first-order conditions which define the optimal institutional arrangements for the central bank. There are two possible solutions here. One is $\delta_{i}=1$ and $\lambda_{i}^{c b}=\lambda_{i 1}^{g}$. This solution characterizes a central bank which is fully dependent. But given $0 \leq \delta_{i}<1$ and $\lambda_{i}^{c b} \neq \lambda_{i 1}^{g},(14)$ and (15) are also satisfied when

$$
\delta_{i}=\frac{\beta_{i} \phi_{i}^{2} \lambda_{i}^{c b} \lambda_{i 2}^{g}+\left(\alpha_{i} \gamma_{i}\right)^{2} \beta_{i} s_{i}^{2}\left(\lambda_{i}^{c b}-\lambda_{i 1}^{g}\right)}{\beta_{i} \phi_{i}^{2} \lambda_{i}^{c b} \lambda_{2 i}^{g}+\left(\alpha_{i} \gamma_{i}\right)^{2} \beta_{i} s^{2}\left(\lambda_{i}^{c b}-\lambda_{i 1}^{g}\right)-\phi_{i}\left[\beta_{i} \phi_{i}+\gamma_{i} \Lambda_{i}\right] \lambda_{i 1}^{g} \lambda_{i 2}^{g}} .
$$

Or, equivalently, when

$$
\lambda_{i}^{c b}=\frac{\left(\alpha_{i} \gamma_{i} s_{i}\right)^{2} \lambda_{i 1}^{g}}{\lambda_{i 2}^{g} \phi_{i}^{2}+\left(\alpha_{i} \gamma_{i} s_{i}\right)^{2}}-\frac{\phi_{i} \delta_{i}\left(\beta_{i} \phi_{i}+\gamma_{i} \Lambda_{i}\right) \lambda_{i 1}^{g} \lambda_{i 2}^{g}}{\left[\lambda_{i 2}^{g} \phi_{i}^{2}+\left(\alpha_{i} \gamma_{i} s_{i}\right)^{2}\right] \beta_{i}\left(1-\delta_{i}\right)}
$$

Now substituting (11)-(13) into (9), and then $\delta_{i}=1$ and $\lambda_{i}^{c b}=\lambda_{i 1}^{g}$ into the result, gives

$$
E L_{i}^{g}=\left(\lambda_{i 1}^{g}\right)^{2} / 2 \alpha_{i}^{2}
$$

But substituting (16) into (9) with (11)-(13) instead, yields

$$
E L_{i}^{g}=\frac{\left(\lambda_{i 1}^{g}\right)^{2}}{2 \alpha_{i}^{2}}\left\{\frac{\left(\alpha_{i} \gamma_{i} s_{i}\right)^{2}}{\left(\alpha_{i} \gamma_{i} s_{i}\right)^{2}+\phi_{i}^{2} \lambda_{i 2}^{g}}\right\}
$$

Since $\lambda_{i 2}^{g} \geq 0$, the value of (18) always exceeds (is no less than) the value of (19). Thus (16) and (17) are the solution to society's optimal central bank design problem. 


\section{Some Important Special Cases}

The solution to our central bank design problem shows that the appropriate degree of conservatism in monetary policy depends on the degree of independence that has been chosen for the central bank. Thus full independence $\left(\delta_{i}=0\right)$ is not necessary for credibility and optimality in monetary policy. Less than full independence can be compensated by greater conservatism. ${ }^{5}$ Consequently we don't actually need any particular monetary policy regime, or central bank independence, or even a particular degree of conservatism, to achieve credibility. Any appropriate combination of those factors, as defined by (16) or (17), will do just as well.

Our model also demonstrates that independence and the degree of conservatism are a joint decision — as emphasized by Rogoff (1985) and Alesina and Gatti (1995). Our analysis differs from these earlier contributions in that, within the context of our model, we explicitly derive the optimal relationship between central bank independence and conservatism. This allows us to determine how the optimal degree of conservatism is affected by changes in the degree of central bank independence. In this section, we consider three cases of special interest: (1) full independence, an example of which is provided by the ECB; (2) partial independence in which there is instrument, but not target independence, as is found in the Bank of England; and (3) various intermediate cases where there is instrument independence and a restricted degree of target independence as in the Federal Reserve System.

\subsection{Full Independence}

Full independence, $\delta_{i}=0$, implies that the optimal degree of conservatism is

$$
\lambda_{i}^{c b *}=\frac{\left(\alpha_{i} \gamma_{i} s_{i}\right)^{2} \lambda_{i 1}^{g}}{\left(\alpha_{i} \gamma_{i} s_{i}\right)^{2}+\phi_{i}^{2} \lambda_{i 2}^{g}}
$$

which is always more conservative $\left(\lambda_{i}^{c b y}<\lambda_{i 1}^{g}\right)$ than society would have chosen for

\footnotetext{
${ }^{5}$ This follows from the fact that (17) implies $\partial \lambda_{i}^{c b} / \partial \delta_{i}=-\phi_{i}\left(\beta_{i} \phi_{i}+\gamma_{i} \Lambda_{i}\right) \lambda_{i 1}^{g} \lambda_{i 2}^{g} /\left[\left(\alpha_{i} \gamma_{i} s_{i}\right)^{2}+\right.$ $\left.\lambda_{i 2}^{g} \phi_{i}^{2}\right] \beta_{i}\left(1-\delta_{i}\right)^{2}$ is negative if the central bank has been designed optimally.
} 
itself provided society also has some social equality objectives: $\lambda_{i 2}^{g}>0$. That is consistent with Rogoff (1985).

\subsection{Partial Independence}

Less than full independence, $0<\delta_{i}<1$, implies an even more conservative central bank since the second term of (17) reduces the optimal value of $\lambda_{i}^{c b}$. We can check that Rogoff's conservative central banker result continues to apply by noting that (8) implies that the central bank being more conservative than the elected government if $\lambda_{i}^{c b}-\delta_{i}\left(\lambda_{i 1}^{g}-\lambda_{i}^{c b}\right)<\lambda_{i 1}^{g}$, i.e. if $\lambda_{i}^{c b}<\lambda_{i 1}^{g}$. That holds for any $0 \leq \delta_{i} \leq 1$ if

$$
\frac{\left(\alpha_{i} \gamma_{i} s_{i}\right)^{2}}{\left(\alpha_{i} \gamma_{i} s_{i}\right)^{2}+\lambda_{i 2}^{g} \phi_{i}^{2}}-\frac{\phi_{i} \delta_{i}\left(\beta_{i} \phi_{i}+\gamma_{i} \Lambda_{i}\right) \lambda_{i 2}^{g}}{\left(\left(\alpha_{i} \gamma_{i} s_{i}\right)^{2}+\lambda_{i 2}^{g} \phi_{i}^{2}\right) \beta_{i}\left(1-\delta_{i}\right)}<1,
$$

which is certainly satisfied for all $\lambda_{i 2}^{g}>0$. But we get equality if $\lambda_{i 2}^{g}=0$. Hence we have shown that Rogoff's conservative central banker does indeed remain optimal even when fiscal policy is introduced - but only so long as society (the government) has some social equality or redistribution objectives. Otherwise it is always best, for any degree of independence, to have the central bank only as conservative as society itself.

It is obvious from (17) that weak independence may require extreme conservatism in monetary policy, and that $\lambda_{i}^{c b}$ may even turn negative as $\delta_{i} \rightarrow 1$ (though not if $\left.\lambda_{i 2}^{g}=0\right) .{ }^{6}$ There are therefore two more cases of special interest. The first is the case where $\lambda_{i}^{c b}=0$ is required; and the second where the composite parameter on $y_{i}$ in (8) turns negative (i.e. when $\left.\lambda_{i}^{c b} \leq-\left[\delta_{i} /\left(1-\delta_{i}\right)\right] \lambda_{i 1}^{g}\right)$. Since (17) implies $\partial \lambda_{i}^{c b} / \partial \delta_{i}<0$, we know $\lambda_{i}^{c b}$ will fall as $\delta_{i}$ rises — passing from a positive value at $\delta_{i}=0$, to $\lambda_{i}^{c b}=0$ at some $\delta_{i}^{L}$, and on to a negative value at $\delta_{i}^{U}>\delta_{i}^{L}$. Each time, the central bank is downgrading its preference/priority for growth, relative to the government's (society's) desire for growth. The impact of independence on the policy

\footnotetext{
${ }^{6}$ This may appear strange, but we are concerned with a two player game in which the growth target enters linearly, and with a weight of $\left(1-\delta_{i}\right) \lambda_{i}^{c b}+\delta_{i} \lambda_{i 1}^{g}$, for the central bank. So the second order conditions for an optimum will be preserved even if $\lambda_{i}^{c b}$ turns negative.
} 
actions of an optimally conservative central bank can be summarized as follows:

i) $0 \leq \delta_{i}<\delta_{i}^{L}$, the central bank is making its own contribution to securing a certain degree of growth from its monetary policy (along side the government);

ii) $\delta_{i}^{L}<\delta_{i} \leq \delta_{i}^{U}$, the central bank starts to moderate the government's desire for growth by adding a smaller negative preference for growth alongside the government's positive preference; and

iii) $\delta_{i}^{U}<\delta_{i}$, the central bank tries to suppress growth by adding a negative preference which actually outweighs the government's positive preference. ${ }^{7}$

It is easy to see that

$$
\delta_{i}^{L}=\frac{\left(\alpha_{i} \gamma_{i} s_{i}\right)^{2} \beta_{i}}{\left(\alpha_{i} \gamma_{i} s_{i}\right)^{2} \beta_{i}+\lambda_{i 2}^{g} \phi_{i}\left(\beta_{i} \phi_{i}+\gamma_{i} \Lambda_{i}\right)}<1
$$

and

$$
\delta_{i}^{U}=\left(\alpha_{i} s_{i}\right)^{2} \beta_{i} \gamma_{i} /\left(\phi_{i} \Lambda_{i} \lambda_{i 2}^{g}\right)
$$

from $(17)$ when $\delta_{i} \leq 1$. These formulae allow us to calculate the point at which the central bank will start restraining the governments desire to create growth; and the point at which it will move to actually trying to suppress growth.

\section{Empirical Evidence}

In order to get some feel for what the results derived above might mean for the design of monetary policy in practice, we have calculated the independence and conservatism parameters, and the associated performance index values, under different configurations of the central bank for eight countries. Our sample consists of countries that have recently and very publicly reformed their monetary policy frameworks with the explicit aim of securing lower and more stable inflation rates without damaging the prospects for growth or output stability.

The eight countries selected fall into three groups:

${ }^{7}$ The finding that $\delta_{i}>\delta_{i}^{u}$ would lead policy makers to choose $\lambda_{i}^{c b}<0$, provides a theoretical explanation for why Eijffinger and Hoebrichts (1998) found the optimal degree of conservatism to be negative for six of the twelve EU countries in their study. 
(a) Eurozone countries: Germany, France and Italy

(b) Non-EMU countries with explicit inflation targets: Sweden and the UK

(c) Implicit inflation targetters: New Zealand, Canada and the US.

Each of these countries (the US excepted) has revised the statutes and the way in which the central bank is required to conduct monetary policy over the past five to ten years. In each case the creation of an independent central bank (whether fully , or only instrument, independent) has been the key feature of the reform. The degree of conservatism and the priority for growth or redistribution has not been discussed, beyond a mention of the need to maintain (an unspecified) degree of "flexibility." Indeed the first group did not discuss the appropriate degree of conservatism at all: it has proved impossible to get any statement on the priority for the "second pillar" of monetary policy relative to the first, from the European Central Bank. The third group has proved most the flexible, with an inflation target incorporated in an inflation contract mechanism. ${ }^{8}$ Although the US has not been through any legal changes, the conduct of monetary policy has clearly changed under Greenspan, and the success of his policies is often held up as an example to others. So the US makes a convenient point of comparison in this exercise.

Table 1 reports the parameter values needed under three different configurations of the central bank: full independence; partial independence with growth restrained; and partial independence where growth needs to be suppressed. These parameters reflect three alternative configurations for an optimal central bank. ${ }^{9}$ Whether growth is actually restrained or suppressed will then depend on what the government decides to do with its fiscal policies, given the institutional design. We therefore include the objective function values for the government. Specifically, we have calculated the government's expected loss when (1) there is an optimally configured central bank, (2) the central bank is fully independent and disregards all noninflation targets (a pure price stability strategy), and (3) the central bank is completely dependent

\footnotetext{
${ }^{8}$ Walsh (1995).

${ }^{9}$ These configurations are all optimal, or approximately optimal, in the sense of Section 3.
} 
$\left(\delta_{i}=1, \lambda_{i}^{c b}=\lambda_{i 1}^{g}\right)$.

The results show that, in line with much of the recent literature, complete dependence is extremely unfavourable. ${ }^{10}$ But the degree to which it is unfavourable varies considerably. Italy, and perhaps the UK or Sweden, would be less concerned about dependence. Given a weak political system (Italy), or a strong commitment to social equality (Sweden) and growth (the UK), these results may explain much of the post war history of those countries.

Second, the ideal level of conservatism, given full independence, is rather small (see column 1). But that also varies considerably across countries. The US would like monetary policies to be 14 times more liberal than Germany; Italy 18 times, the UK 7 times, and so on. It is clear that there is a great deal more variation in the priority to be given to growth within the Eurozone, than within either of the other groups; or between the Eurozone and the other two groups. Much of that variation is due to Italy however. If we take Italy out, the Eurozone starts to look a lot like the other two groups - but significantly less liberal than the US.

The same variations can be seen in the values for $\delta_{i}^{L}$ (the level of independence at which the central bank will start to intervene to restrain the government's growth policies) and in $\delta_{i}^{U}$ (the level of independence at which the central bank will start to counteract and suppress the government's desire for growth). However the significant point about those figures is that they are all small. Any small retreat from complete independence would almost immediately lead the central bank, if it is operating optimally, to restrain or even suppress the governments' desire for growth. It is impossible to imagine that governments drafting the institutional arrangements for monetary policies would admit that they were trying to create a central bank that was in all probability going to restrain, if not suppress growth. It would be better, and certainly politically more realistic, to go to the full independence solution - and stress that the Central Bank's policies will at least be contributing to growth and

\footnotetext{
${ }^{10}$ The parameter values that we have used to make these calculations are reported in the appendix to this paper.
} 
redistribution, along with the discipline to maintain low inflation. The reason for stressing the virtues of central bank independence ahead of conservatism in policy, must therefore be political.

\section{Independence, Conservatism, and Transparency}

The agents in our model have full information about the structure of the economy and the preferences of the policy authorities. They are therefore able to determine whether the observed monetary policy is consistent with an optimal combination of central bank independence and conservatism. In practive, agents are likely to be less well informed with respect to the underlying structure of the economy and the institutional constraints that govern the interactions between monetary and fiscal authorities. Over time, policy makers have come to realize that policy credibility, and therefore effectiveness, can be enhanced by policy transparency; i.e., by improving the public's information set. ${ }^{11}$

In our model, policy transparency could be implemented by communicating to the public information about three key variables: the inflation target $\hat{\pi}$, the degree of central bank independence $\delta_{i}$, and the degree of central bank conservatism $\lambda^{c b}{ }^{12}$ From a theoretical standpoint, it should not matter which combination of these variables the policy authorities announce provided that (16) is satisfied. However, from a practical perspective, there may be both economic and political reasons for preferring one combination to another.

Our results show that the optimal degree of divergence between the priorities assigned to growth by the central bank and the government is decreasing in the degree of central bank independence (given $\lambda_{i 2}^{g} \neq 0$ ). Specifically, as the degree of independence is reduced, there are thresholds where it becomes necessary to appoint central

\footnotetext{
${ }^{11}$ Blinder (1998) and Faust and Svensson (2001) argue that transparency in monetary policy allows the private sector (and other policy makers) to make better and better informed decisions.

${ }^{12}$ We assume that $\lambda_{i 1}^{g}$ reflects the average of the electorate's preferences and is known to the public.
} 
bankers who will assign less and less weight, and ultimately a negative weight, to the growth objective. Consequently, as the divergence between the public's preferences (as reflected by $\lambda_{i 1}^{g}$ ) and those of the central bank increases, the public is less and less likely to accept the central bank's conservatism as being compatible with its own preferences. This divergence in preferences may also be perceived by the public as a disagreement between the government and the central bank. In either case, the public's perception that the central bank is too conservative will undermine the effectiveness of the policy program. Financial markets do not respond well to the uncertainty that inevitably accompanies perceived incompatibilities between monetary and fiscal policy. Furthermore, the government's electoral prospects are likely to suffer if voters suspect that their preferences are being ignored. Under these circumstances, both the government and the central bank may find full transparency counter-productive. ${ }^{13}$

Policy transparency is useful if it enhances the effectiveness of monetary and fiscal policy. The foregoing discussion suggests that transparency is most effective when the central bank is fully independent. Setting $\delta_{i}=0$ minimizes the optimal divergence between $\lambda_{i}^{c b}$ and $\lambda_{i 1}^{g}$ and thus reduces the likelihood that the public will perceive central bank conservatism as being too extreme. Consequently, full independence maximizes the potential flexibility, or room to manoevre, in the central bank's policy responses to changes in the economic environment. The calculations for the eight OECD countries which we report in Table 1 show the threshold values, $\delta_{i}^{u}$, at which it becomes optimal to appoint central bankers who have a preference for restraining output growth (i.e., who would set $\lambda_{i}^{c b}<0$ ) to be extremely small. These results therefore support our contention that monetary policy will be most effective when governments grant their central banks full independence.

The foregoing discussion has an interesting implication for empirical studies of

\footnotetext{
${ }^{13}$ Issing (1999) argues that the central bank may want to limit transparency under some circumstances. The impact of the choice of $\delta_{i}$ on $\lambda_{i}^{c b}$ in our model, identifies the source of Issing's argument for limiting transparency.
} 
the relationship between central bank independence and inflation performance. Weymark (2001) uses a model similar to the one employed here to show that there is, in theory, no causal relationship between central bank independence and inflation; both variables are jointly determined by the underlying structural characteristics of the economy and by the preferences of the policy authorities. ${ }^{14}$ Our discussion in this section provides a practical, and also political, explanation for the negative relationship between central bank independence and inflation that has been found so many empirical studies. Specifically, our analysis suggests that central bank independence improves inflation performance because the optimal divergence between the weights that the government and the central bank assign to output growth decreases as central bank independence increases, and this enhances the benefits of policy transparency and, therefore, the effectiveness of monetary policy.

\section{Conclusion}

Rogoff (1985) shows that inflationary bias is reduced when the central bank is more conservative than society in the importance it assigns to the economy's output performance. Our analysis shows that this result is robust to the inclusion of a fiscal authority whose policies interact with those of the central bank, but only if the government attaches some positive weight to the provision of public goods or income redistribution objectives.

Earlier studies of institutional design, proceeding from the assumption that full central bank independence is necessary for effective monetary policy, have treated independence as exogenous. In our model, by contrast, central bank indpendence is endogenously determined. The results of our analysis show that, from a theoretical perspective, there is no reason to prefer full independence over any other alternative. In principle, monetary policy is equally effective under all of the possible optimal combinations of central bank independence and conservatism.

\footnotetext{
${ }^{14}$ This outcome provides a theoretical justification for Posen's (1995) often quoted argument that there may be a reverse causality from inflation aversion to central bank design.
} 
From a practical perspective, however, there may be compelling reasons to choose full independence over its alternatives. Our results show that the optimal degree of divergence between the weights that the central bank and the government assign to output growth is decreasing in the degree of central bank independence. Given the preferences of the elected government and the underlying structure of the economy, a less independent central bank must exhibit a greater degree of conservatism than a central bank that has been granted more independence. We argue above that this theoretical result has an important political implication. In particular, because public support is likely to diminish as the perceived conservatism of the central bank increases, relative to public preferences, central banks that are less independent have an incentive to limit policy transparency. This line of reasoning suggests that policy transparency, and therefore monetary policy, will be most effective when central banks are fully independent. The practical implication of our theoretical results is therefore to resurrect the positive relationship between economic outcomes and central bank independence.

Our approach unites a number of themes that appear in the literature on central bank design. First, we provide a theory for appointing conservative central bankers which is not restricted to full independence, a single policy instrument, or one set of electoral probabilities. Second, we explain how transparency and political considerations may influence the choice of institutional design. We also offer an explanation of how credibility-flexibility debates can arise and be resolved. Finally, we provide a theory that reconciles the contradictory results that have been obtained in empirical studies of the relationship between central bank independence and inflation. There are, nevertheless, several restrictions remaining in our work. Relaxing these restrictions to allow for central bank leadership, different inflation targets (and inflation targeting where the government selects the target values in particular), and different forms of deficit financing, are extensions to our basic model that we plan to consider in future research. 


\section{References}

Alesina, A. and R. Gatti (1995) "Independent Central Banks: Low Inflation at No Cost," American Economic Review 85, 196-200.

Alesina, A. and G. Tabellini (1987) "Rules and Discretion with Noncoordinated Monetary and Fiscal Policies," Economic Inquiry XXV, 1987, 619-630.

Blinder, A.S. (1998) Central Banking in Theory and Practice, Cambridge, Mass.: MIT Press.

Cukierman, A. (1992) Central bank Strategy, Credibility, and Independence, Cambridge, Mass.: MIT Press.

Debelle, G. and S. Fischer (1994) "How Independent Should a Central Bank Be?" In Jeffrey C. Fuhrer (ed.) Goals, Guidelines, and Constraints Facing Monetary Policymakers, Federal Reserve Bank of Boston Conference Series 38, 195-221.

Dixit, A.K. (2000) "A Repeated Game Model of Monetary Union," Economic Journal 110, 759-80.

Dixit, A.K. (2001) "Games of Monetary and Fiscal Interaction in the EMU," European Economic Review 45, 589-613.

Eijffinger, S.C.W. and M. Hoebrichts (1998) "The Trade-Off Between Central Bank Independence and Conservativeness," Oxford Economic Papers 50, 397-411.

Eijffinger, S.C.W. and E. Schaling (1996) "The Ultimate Determinants of Central Bank Independence," in S. Eijffinger and H. Huizinga (eds.) Positive Political Economy: Theory and Evidence, Cambridge, UK: Cambridge University Press, $47-74$

Faust, J. and L.E.O. Svensson (2001) "Transparency and Credibility: Monetary Policy with Unobservable Goals," International Economic Review 42, 36-397.

Fischer, S. (1995) "Central Bank Independence Revisited," American Economic Review 85, 201-6.

Flood, R. and P. Isard (1989) "Monetary Policy Strategies," International Monetary Fund Staff Papers 36, 612-32

Hughes Hallett, A. and D.N. Weymark (2001) "The Cost of Heterogeneity in a Mone- 
tary Union," Discussion Paper No. 3223, Center for Economic Policy Research, London; Working Paper No. 01-W28, Department of Economics, Vanderbilt University, <www.vanderbilt.edu/econ>.

Issing, O. (1999) "The Euro System: Transparent and Accountable," Jpournal of Common Market Studies 37, 503-20.

Lohmann, S. (1992) "Optimal Commitment in Monetary Policy: Credibility versus Flexibility," American Economic Review 82, 273-86.

Lucas, R.E. (1973) "Some International Evidence on Output-Inflation Trade-Offs," American Economic Review 63, 326-34.

Lucas, R.E. (1972) "Expectations and the Neutrality of Money," Journal of Economic Theory 4, 103-24.

McCallum, B.T. (1989) Monetary Economics: Theory and Policy, MacMillan, New York.

Posen, A.S. (1995) "Is Central Bank Independence (and Low Inflation) the Result of Effective Fianacial Opposition to Inflation

Rogoff, K. (1985) "The Optimal Degree of Commitment to an Intermediate Monetary Target," Quarterly Journal of Economics 100, 1169-89.

Taylor, J.B. (1993) Macroeconomic Policy in a World Economy: From Econometric Design to Practical Operation, W.W. Norton and Company, New York.

Turner, D., and E. Seghezza (1999) "Testing for a Common OECD Phillips Curve," Working Paper No. 219, Economics Department, OECD, Paris.

Walsh, C.E. (1995) "Optimal Contracts for Central Bankers," American Economic Review 85, 150-167.

Weymark, D. N. (2001) "Inflation, Income Redistribution, and Optimal Central Bank Independence," Working Paper No. 01-W02R, Department of Economics, Vanderbilt University. <www.vanderbilt.edu/econ>.

\section{Appendix}

The parameter values used in Section 5 are set out in Table 2. They come from dif- 
ferent sources, and are offered as "best practice" estimates of the relevant parameters for a stylized facts analysis. The advantages of further econometric refinements, or consistency constraints on the underlying econometric specifications, would be lost if we varied the parameter values to capture the effects of different preference or transmission asymmetries on performance.

The Phillips curve parameters, $\alpha_{i}$ from (1), are taken as the inverse of the annualized sacrifice ratios estimated on quarterly data from 1971-1998 by Turner and Seghezza (1999). ${ }^{15}$ From (2), $\beta_{i}$ and $\gamma_{i}$ measure the effectiveness of monetary and fiscal policy, respectively. We obtained the $\beta_{i}$ and $\gamma_{i}$ values reported in Table 1 from John Taylor's (1993) multicountry econometric model. These parameter values are the simulated one-year multipliers for each economy, jointly estimated in a model of interdependent economies. Thus, although our model (1)-(3) does not make spillovers between economies explicit, our numerical estimates do reflect the performance of an economy subject to such spillovers.

The national savings ratios $s_{i}$ were obtained from OECD data (Economic Outlook, various issues). We chose to use the 1998 data because that was the year in which EMU started. We also used 1998 OECD data to estimate the desired level of income equality $\theta_{i}$. According to our model, $\theta_{i}$ measures the desired degree of income equality in terms of the desired proportion of output allocated to the rich. We therefore estimate $\theta_{i}$ as one minus the proportion of total fiscal expenditure allocated to social expenditures in each country.

Finally, $\lambda_{i 1}^{g}$ and $\lambda_{i 2}^{g}$ represent the $i$ th country's preference for growth and income redistribution, respectively, relative to a unit penalty for inflation aversion. For lack of any direct evidence on these preference parameters, we have set $\lambda_{i}^{g 1}=1$ and $\lambda_{i 2}^{g}=0.5$, for each $i$.

\footnotetext{
${ }^{15}$ Turner and Seghezza (1999) also note that there is no significant difference between the numerical estimates obtained from single-country estimation and OECD-wide systems estimation. This justifies our use of single country estimates in (1)-(3) for economies that are subject to spillover effects.
} 


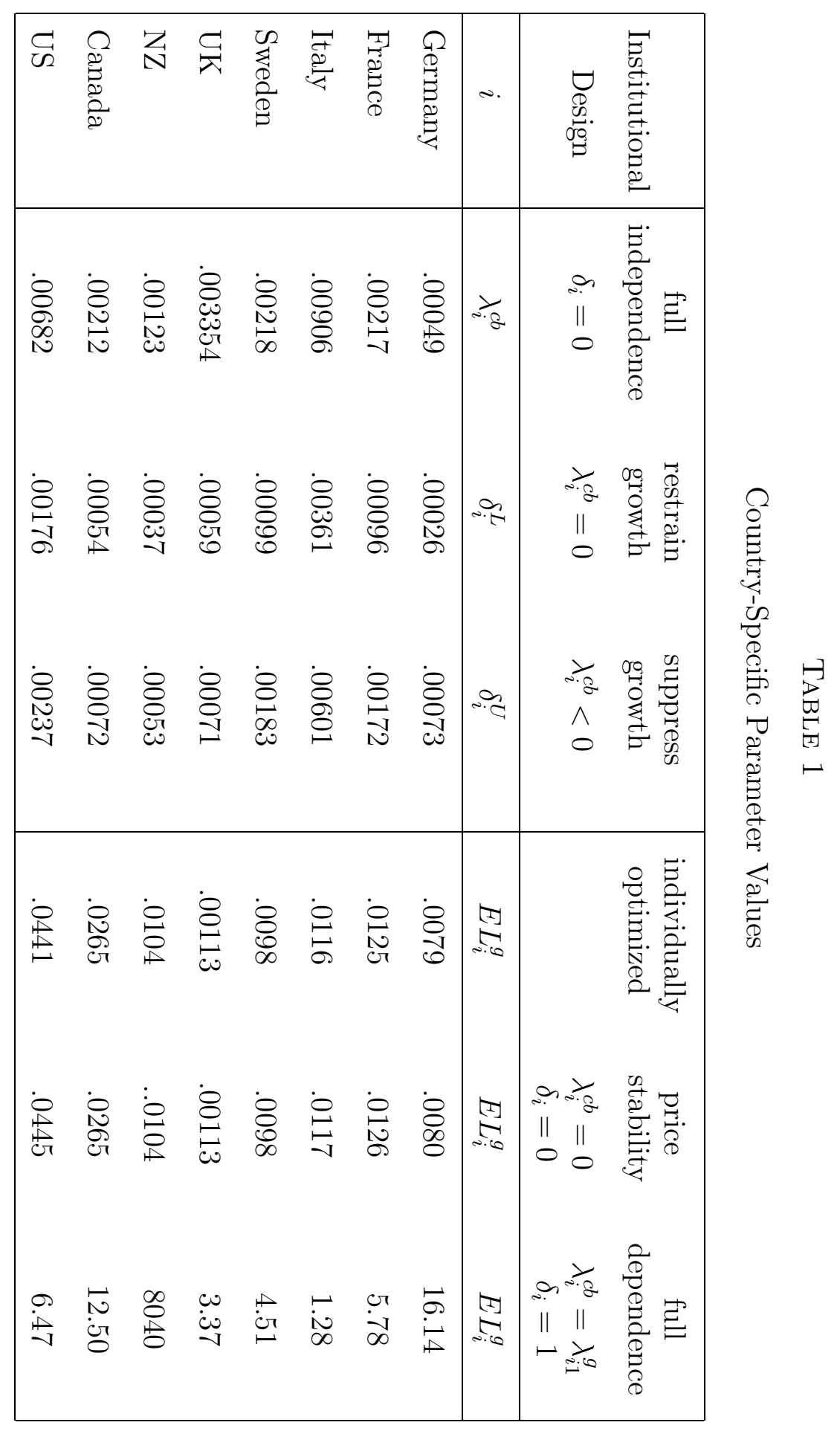


TABle 2

Country-Specific Parameter Values

\begin{tabular}{|l|cccccc|}
\hline \multicolumn{1}{|c|}{$i$} & $\alpha_{i}$ & $\beta_{i}$ & $\gamma_{i}$ & $s_{i}$ & $\theta_{i}$ & $\phi_{i}$ \\
\hline Germany & 0.176 & 0.533 & 0.43 & 0.216 & 0.583 & 1.040 \\
France & 0.294 & 0.500 & 0.57 & 0.211 & 0.620 & 1.072 \\
Italy & 0.625 & 0.433 & 0.60 & 0.214 & 0.651 & 1.187 \\
UK & 0.385 & 0.133 & 0.58 & 0.180 & 0.675 & 0.980 \\
Sweden & 0.333 & 0.489 & 0.533 & 0.206 & 0.504 & 1.107 \\
New Zealand & 0.244 & 0.400 & 0.850 & 0.124 & 0.596 & 1.035 \\
Canada & 0.200 & 0.400 & 0.850 & 0.185 & 0.725 & 0.966 \\
US & 0.278 & 0.467 & 1.150 & 0.184 & 0.597 & 1.004 \\
\hline
\end{tabular}

